\title{
Políticas educacionais contemporâneas: tecnologias, imaginários e regimes éticos*
}

\author{
Maria Manuela Alves Garcia \\ Universidade Federal de Pelotas, Faculdade de Educação
}

O tema das reformas das políticas educacionais que vem alterando, de modo alargado e profundo, desde os anos de 1990, a educação brasileira em todos os níveis - já é lugar comum, mas sempre importante na agenda de nossas discussões. Abordar esse tema de uma perspectiva tal que possa articular novas ideias, ou outros olhares, sobre as transformações que vimos assistindo, é um desafio.

Inspirada em um conjunto de estudos que problematizam o caráter global das reformas educacionais das últimas décadas e nos estudos de Michel Foucault acerca do discurso (1995) e da governamentalidade (1990), examino a racionalidade que tem pautado especificamente alguns documentos oficiais, destacando suas principais tecnologias de governo e relações com a produção de certos imaginários sociais e regimes éticos dos indivíduos. Trata-se de um estudo de cará-

* Este texto foi apresentado pela primeira vez em sessão especial do GT de Currículo e GT de Políticas Educacionais na $31^{\mathrm{a}}$ Reunião Anual da Associação Nacional da Pós-Graduação em Educação (ANPEd), em 2008, Caxambú-MG.

ter exploratório, sem forte preocupação com análises exaustivas dos documentos que examino ou mesmo dos contextos históricos que os delimitam. Baseio minhas observações em análises de outros estudos com a mesma preocupação e em minha própria experiência de pesquisadora relativa às transformações por que vêm passando a profissionalização e o trabalho docente no Brasil (Anadon \& Garcia, 2005; Garcia, 2008; Garcia \& Anadon, 2009). Para descrever, a título de ilustração, os imaginários sociais e éticos acerca da educação e da cidadania, propostos pelos discursos das reformas, trago ao texto observações e enunciados que percorrem documentos oficiais promovidos tanto por organismos internacionais e supranacionais, como nacionais, que se dirigem a estabelecer metas para a educação no mundo e no Brasil e transformar os currículos da educação básica e da educação de professores.

Meu olhar sobre os documentos aqui analisados está ocupado pelos modos como os discursos das reformas interpelam os indivíduos, inscrevendo-os em posições sociais e em determinadas formas de existência, com suas esperanças e temores. A análise desses discursos deteve-se sobre os enunciados que apontam 
para as formas de identidade e atuação desejadas para o sujeito econômico, político, educacional etc., fixadas e construídas, no próprio discurso, em relação ao seu outro e às suas diferenças.

As reformas atuais são práticas globais que visam a mudanças nos padrões de regulação social e nos regimes éticos que capacitam os sujeitos para as relações sociais. As reformas incorporam sistemas de razão e conhecimento como práticas de inclusão e exclusão que produzem posições de sujeito, sistemas de classificações e distinções, que formam o horizonte ético do indivíduo consigo mesmo e com os outros. As reformas, além de serem um conjunto de direções e princípios, e políticas, que devem guiar o trabalho escolar e docente, são esforços calculados para inscrever certas racionalidades políticas nas sensibilidades, nas disposições e na consciência dos indivíduos, capacitando-os diferentemente para a ação e a participação no mundo (Popkewitz, 1997, 2004).

"A reforma é a administração da liberdade personificada em sistemas de conhecimento profissionais e especializados". Isso implica racionalizações específicas que de modo geral estão ligadas à burocracia, seja ela do Estado ou dos organismos internacionais e supranacionais, que desempenham no mundo globalizado funções específicas e outras tradicionalmente associadas ao aparelho de Estado. Além disso, essas racionalizações estão relacionadas a sistemas de conhecimento produzidos pelas disciplinas das ciências sociais (Popkewitz, 2004, p. 111).

O problema das reformas, e também das políticas educacionais, é centralmente o problema da mudança nas capacidades interiores, cognitivas e instrumentais dos indivíduos, de modo que essas mudanças coincidam com os objetivos da administração social das populações. As reformas e as políticas estão relacionadas com a gestão dos indivíduos e das agências encarregadas de educar esses indivíduos. Para isso, estabelecem uma série de regulamentações, mobilizam discursos e tecnologias (como o currículo, a didática, modalidades de organização e gestão escolar etc.), tornando a alma e as capacidades humanas objetos de disputa e governo.
Esse não é um fenômeno novo. Desde as reformas sociais da Europa e da América do Norte no século XIX, relaciona-se com a construção moderna de Estado como um aparato legal e administrativo para cuidar não somente dos limites territoriais, mas, sobretudo, de suas populações, visando o progresso, utilidade, desenvolvimento, conquista, alargamento de territórios e influências. A escolarização de massas tem sido um dispositivo fundamental na construção de regimes éticos do indivíduo, assentados na agência, na autonomia regulada e na responsabilidade. Sistemas de conhecimento com efeitos de verdade unem as práticas de reforma à administração das populações. A psicologia da criança, os conhecimentos acerca da infância e a pedagogia decretaram princípios para a construção de cidadãos, trabalhadores autorresponsáveis e automotivados (Popkewitz, 2004).

As políticas educacionais instituem e incorporam uma economia de poder, um conjunto de tecnologias e práticas, associações, experts, discursos "dominantes" e regimes de verdade que formam uma rede e um complexo necessário para o alinhamento de decisões e ações que, contemporaneamente, exercem um "governo à distância" (Rose, 1996). As políticas educacionais fazem parte dessas estratégias que tentam tornar o mundo legível e transparente, anular a contingência e o acontecimento, por meio da manipulação da incerteza e dos cálculos da burocracia moderna, que sonha com a uniformidade $\mathrm{e}$ a regularidade de um mundo em ordem (Bauman, 1999).

Quero situar a seguir o problema das reformas e das políticas educacionais atuais no interior do sistema de razão que as anima, denominado, pela maioria dos autores entre nós, neoliberalismo, e por outros, como Rose (1996), "liberalismo avançado". Ambos os termos pretendem uma diferenciação seja do liberalismo clássico do século XIX, seja do liberalismo do Estado de bem-estar, e nomeiam as profundas transformações políticas e econômicas que têm pautado a gestão do Estado e das populações em tempos de globalização. 


\section{Globalização e governamentalidade neoliberal}

O sentimento de estar no centro de largas e profundas transformações em curso, tanto do ponto de vista econômico, social e político, como cultural e educacional, é o sentimento de nossa era e aspecto reiterado insistentemente pelos discursos que justificam as reformas e as ações dos economistas de plantão nas burocracias dos aparatos oficiais de governo nacionais e não nacionais.

A globalização não é um fenômeno novo. Uma periodização de longo termo, diz McKeown (2007, p. 220), protege-nos dos profetas da novidade e colocanos diante do fato de que os fluxos globais remontam pelo menos ao início do século XIX, e estiveram historicamente implicados na produção e reconstituição de fronteiras e em movimentos de homogeneização e hibridização. As interações globais desde essa época cresceram lado a lado com a emergência de nações, da racialização, das etnicidades, burocracias, fundamentalismos, tradições reificadas, autenticidades, discursos de civilização e barbarismos, os Terceiros Mundos e as áreas de estudo que modelam muito do conhecimento global contemporâneo.

A "novidade" e o "esquecimento" que têm acompanhado os discursos da globalização e da reforma são estratégias discursivas que investem no apagamento do passado e no desenho do futuro, contribuindo para a fabricação de um novo senso comum que considera o rumo do capitalismo e da história como algo inevitável e inexorável. As promessas e as falhas da modernização e da educação modernas são esquecidas, bem como as desiguais consequências que os fluxos globais têm tomado, evidenciando a capacidade de autorrenovação que a Modernidade e o capitalismo têm tido nos últimos séculos.

A globalização contemporânea, cujas mudanças específicas em alguns países da Europa e nos EUA são mais visíveis nos anos pós 1970, diferencia-se por mudanças nos padrões de acumulação capitalista, nos fluxos emigratórios e na intensificação das desigualdades sociais e globais. Passou-se de um capitalismo cuja produção de valor se dava na esfera da produção para um capitalismo cuja produção de valor se dá na esfera da circulação e no cálculo do risco. O resultado é o enfraquecimento dos movimentos sindicais e das lutas trabalhistas, em meio a uma conjuntura de ajustes estruturais e altas taxas de desemprego nos países em desenvolvimento. Juntamente com os fluxos de derivativos, a revolução tecnológica permitiu a compressão do tempo e do espaço na circulação de ideias, de culturas e modos de vida.

É ao redor desse mundo "glocalizado", como caracteriza Bauman (1999), de efeitos ambivalentes entre o global e o local, que os discursos da globalização e as políticas neoliberais viajam, promovidas por organismos supranacionais, encarregados da integração econômica mundial, ajuda e cooperação internacional - Fundo Monetário Internacional (FMI), Organização para Cooperação e Desenvolvimento Econômico (OCDE), Organização das Nações Unidas para a Educação, a Ciência e a Cultura (UNESCO) e Banco Mundial. São discursos que nem sempre convergem, mas que têm em comum a promessa de inclusão, progresso e desenvolvimento, riqueza, democracia, igualdade e qualidade de vida para todos que se inserirem no mercado e na cultura globais.

Um marco dessa atuação no campo político e econômico é o "Consenso de Washington", que, em 1989, estabelece um conjunto de medidas econômicas de cunho neoliberal que passam a ser recomendadas pelo FMI para a aceleração do desenvolvimento econômico nos países da América Latina. Entre essas medidas: disciplina fiscal, redução de gastos públicos, privatizações das estatais, desregulamentação com o "afrouxamento" das leis econômicas e trabalhistas, abertura comercial e eliminação de restrições para os investimentos externos diretos.

No Brasil, desde o início da década de 1990, em que pesem as diferenças ideológicas, sucessivos governos avançaram na direção dessa agenda, com reformas que convergiram para a reforma estrutural do Estado brasileiro. Em janeiro de 1995, Luiz Carlos Bresser Pereira, ministro da Administração Federal e da Reforma do Estado (MARE), do governo de Fernando Henrique Cardoso, avaliava nos 
seminários realizados com os partidos políticos sobre reforma constitucional, promovidos pelo gabinete da Presidência da República, em Brasília, que, desde a restauração da democracia em 1985 e sua consolidação com a Constituição de 1988, o Brasil não enfrentava a causa fundamental das sucessivas crises econômicas que a partir de 1979, com o segundo choque do petróleo, assolavam o país. Dizia ele: "Crise que se define pela crise fiscal do Estado, pela crise do modo da intervenção na economia e do social, e pela crise do aparelho do Estado" (Pereira, 1995, p.2).

Três anos depois dessa fala do ministro, era encaminhada ao Congresso a emenda constitucional n. 19 que alterou dispositivos da Constituição de 1988 referentes aos servidores e à administração pública e possibilitou a reforma do Estado nas bases de um novo gerencialismo, implicando outras estratégias de governo e controle aliadas à intensificação de uma economia de regulação moral dos indivíduos (Peters; Marshall \& Fitzsimons, 2004). Novos imaginários sociais e nacionais foram criados como condições de possibilidade para a inscrição nos indivíduos de outras consciências, disposições e capacidades.

\section{Governamentalidade neoliberal e tecnologias políticas de governo}

O termo "governo" remete a uma racionalidade política que centra sua atenção na "conduta da conduta" ou, em outros termos, na previsão de um campo de possibilidades para a ação dos outros (Foucault, 1990), e para a ação do sujeito sobre si próprio. O Estado na Modernidade tornou-se um Estado de "governo", processo histórico que Foucault (1990) chamou de a governamentalização do Estado moderno. Ou seja, a introdução da arte do governo (entendido como a arte de bem dispor as "coisas" a fim de alcançar riqueza e progresso) ao nível do Estado, atando, no dizer de Popkewitz (1997, p. 38), "o poder que circula através da macroestrutura do Estado ao poder que circula na microestrutura do indivíduo".

Rose (1996), comentando o sentido político que os termos "governo" e "governamentalidade" têm no trabalho de Foucault, coloca essas problemáticas em termos que me ajudam a caracterizar a racionalidade política neoliberal, ou o novo gerencialismo, que está na base das reformas do Estado e dos princípios mais gerais que pautam as reformas educacionais na contemporaneidade. Essas reformas são ao mesmo tempo efeitos dos novos arranjos políticos e econômicos surgidos no pós-guerra e condições de possibilidade da articulação, funcionamento e expansão desses mesmos arranjos.

Como racionalidade política, as governamentalidades devem ser analisadas como práticas, como conjunto de tecnologias de governo, "maquinaria" ou "aparato intelectual" para tornar pensável a realidade, "de tal modo que ela se ajuste ao programa político". E continua Rose (1996):

A despeito de toda mesquinhez e corrupção da atividade política, as racionalidades políticas possuem uma forma moral, na medida em que afetam questões como a adequada distribuição de tarefas entre as diferentes autoridades e os ideais ou princípios a que o governo deve dedicar-se. Além disso, as racionalidades políticas têm um caráter epistemológico, visto que incorporam concepções particulares dos objetos a serem governados - nação, população, economia, sociedade, comunidade - e dos sujeitos a serem governados - cidadãos, sujeitos, indivíduos. E desenvolvem um certo estilo de raciocínio: linguagem aqui compreendida como um conjunto de "técnicas intelectuais" para tornar a realidade pensável e praticável, e constituir domínios que se ajustem - ou não se ajustem - à intervenção reformadora. (idem, p. 42)

O termo "racionalidade" está relacionado a uma certa inteligibilidade, ou à introdução de uma ordem na disposição das coisas e dos objetos a governar, a fim de alcançar resultados e eficiência com custos mínimos ou previsíveis. As racionalidades políticas estabelecem laços entre razão, poder político e estrutura de Estado, considerando que hoje é necessário lidar com uma noção de Estado "ampliado", na qual a clássica distinção entre sociedade civil e Estado é problemática. As racionalidades políticas modernas 
são formas de poder político referidas ao "Estado" e implicam tecnologias de poder individualizador, que passam por regimes de verdade e conhecimento.

A implantação de programas de governo depende "da complexa agregação de diversas forças (legal, arquitetural, profissional, administrativa, financeira, judiciária), técnicas (notação, computação, cálculo, exame, avaliação), instrumentos (levantamentos e gráficos, sistemas de treinamento, formas de construção)" (idem, ibidem), com o objetivo de ordenar decisões e ações de indivíduos, grupos, organizações, em relação a critérios oficiais. Podem ser programas exógenos, elaborados fora das fronteiras do Estado-Nação, ou no interior dessas, quando os definimos como elaborados no interior da Nação. De qualquer modo, esses programas dependem da translação (movimento de um lado para o outro) de pensamento e ação, de uma "central de cálculo" para diferentes sítios dispersos em um território que guardam sua autonomia formal. Por isso mesmo, esses programas necessitam ser reassentados a cada vez. É o alinhamento desses diversos pontos da rede que permite uma ação calculada sobre a conduta através do espaço e do tempo, possibilitando um "governo à distância" (Rose, 1996).

Por exemplo, no campo educacional, organismos como a UNESCO, desde as duas últimas décadas do século XX, têm tido uma importância capital na promoção de reformas e metas educacionais para os países em desenvolvimento, contando com representações regionais - no nosso caso a Oficina Regional de Educação para a América Latina e o Caribe (OREALC) - e escritórios locais, para desenvolver, instrumentalizar e avaliar os programas em curso nos países da região. Nessa direção, esses organismos mobilizam um conjunto de experts, centros estatísticos, bancos de dados, seminários mundiais e regionais, documentos, programas de metas regionais, revistas etc., que, de modo refletido, fazem uma representação da realidade educacional desses países e o alinhamento de diretrizes e metas que efetivamente vêm direcionando as políticas educacionais de cada país, entre eles o Brasil.

Os compromissos e as metas assumidos pelos governos na Conferência Mundial de Educação para
Todos, realizada em Jomtiem, na Tailândia, em 1990, e, posteriormente, os firmados pelos participantes no Fórum Mundial de Educação, realizado em Dakar, dez anos depois, são parâmetros para a orientação das reformas educacionais no Brasil. Não foi uma "feliz coincidência", como assinalam Efrem Maranhão, Sérgio Haddad e Jorge Werthein na apresentação do documento "Educação para todos: o compromisso de Dakar", quando do seu lançamento no Brasil, em 2001, que a discussão do "Marco de Ação de Dakar" no país coincidiu com a aprovação do Plano Nacional de Educação (PNE). Também o Plano de Desenvolvimento Educacional (PDE), lançado pelo ministro Sérgio Haddad em 2007, é uma expressão desses compromissos e metas.

"O neoliberalismo não renuncia à vontade de governar" (Rose, 1996). Simplesmente inventa, ou reestrutura, novas estratégias, que vão no sentido da "desgovernamentalização do Estado" e da "desestatização das práticas de governo", utilizando como estratégias a marketização e o empresariamento dos serviços sociais, a descentralização, a pluralização, a autonomização e a autogestão induzidas pelo Estado, dentro de um mercado governado pela competição, pela responsabilidade e demanda do consumidor.

Nas palavras de Peters, Marshall e Fitzsimons (2004), o novo gerencialismo, como tecnologia política de governo para a organização institucional no campo educacional, aposta na descentralização do controle da gestão para a instituição individual, por meio do estabelecimento de novas formas de financiamento e responsabilização.

Há uma aparente "devolução" dos poderes reguladores do Estado para "baixo", no caso, para as instituições educacionais e seus agentes, ou para as instâncias intermediárias do sistema, no sentido de responsabilização pela gestão dos recursos e currículos e do estímulo ao planejamento, ainda que as metas e diretrizes mais gerais sejam estabelecidas nos "centros de cálculo" e pelos seus documentos oficiais, sejam esses centros os gabinetes do Ministério da Educação, ou a UNESCO, a OREALC, a OCDE etc. 
Como sugere Rose (1996), o problema agora é colocado em termos da "moldagem de vontades de entidades autônomas", sejam empresas, escolas, organizações, comunidades, profissionais, indivíduos, dentro de uma lógica de competição, qualidade e demanda dos "clientes". Atividades e responsabilidades que estavam anteriormente dentro do aparelho político do Estado são reconfiguradas como responsabilidades de uma variedade de organizações não governamentais, voluntários, fundações, empresas, por meio de parcerias, colaborações, "amigos", privatizações, terceirização etc. Contratos, metas, indicadores (como o Índice de Desenvolvimento da Educação Básica - IDEB) e os bancos de dados que resultam dos exames nacionais, por exemplo), currículos prescritos, políticas de avaliação e auditoria garantem o governo à distância e a responsabilização individualizada dentro de metas e estratégias definidas centralmente.

Desde essa perspectiva, emerge o regime do eu, que tem na autonomia, no autoempreendedorismo, na autorresponsabilização e na performatividade características fundamentais. A descentralização e a parceria, como tecnologias políticas de gestão institucional, impõem novas categorias e novos termos para pensar o mundo, a sociedade, os indivíduos, ressignificando termos como qualidade, sucesso escolar, autonomia, cidadania, público, gestão democrática, participação.

\section{As reformas educacionais no Brasil: imaginários sociais e regimes éticos}

Os fluxos de capitais e mercadorias ao redor do mundo têm sido acompanhados de fluxos globais de ideias e culturas, que incorporam modos de vida e determinadas formas de ser e existir. Esperanças e medos são parte desses mesmos fluxos, funcionando ora como perigos a serem evitados e combatidos, ora como promessas e seduções que estimulam modos particulares de pensamento e vida.

Termos como traveling libraries (livrarias que viajam), traveling policies (políticas que viajam) ou ainda indigenous foreigner (estrangeiro indígena) nomeiam esse fluxo de ideias e políticas ao redor do globo e sua apropriação em contextos nacionais. $\mathrm{O}$ caso de J. Dewey é paradigmático desse movimento. Suas ideias, no início do século XX, atravessaram fronteiras e extrapolaram o seu contexto de emergência nos Estados Unidos, sendo incorporadas por discursos e políticas em lugares tão diferentes no mundo, para divulgar as virtudes da ciência e da agência humana no controle do mundo natural e no progresso da sociedade. Um discurso estrangeiro que se tornou indígena, quer dizer, aliou-se a outros e fez amálgamas e híbridos suficientemente diferentes conforme as realidades locais, lançando as bases sobre as quais foram edificadas as reformas da escolarização e a modernização de países tão diferentes como o Brasil, a Colômbia, a Bélgica, Portugal, Suécia, a Turquia, a China, o Japão, o México etc. (Popkewitz, 2005).

Também conceitos como "recontextualização", "ressignificação", "hibridização" dão nome a processos em que estão em jogo as relações entre o global e o local, o geral e o particular, o texto e o contexto, na construção das políticas educacionais e curriculares.

Mesmo considerando as diferenças entre os contextos nacionais na apropriação das tendências "exógenas" das políticas de reforma ou os hibridismos que resultam desses confrontos e negociações, uma questão impõe a unidade na diferença: o aumento da "colonização das políticas educativas pelos imperativos das políticas econômicas”, a revolução tecnológica, e a obsessão com a performatividade dos sistemas (Ball, 2001, p. 100). A presença constante nos textos oficiais de termos como "sociedade do conhecimento", aprendizagem para a vida toda (lifelong learner), educação para a competitividade são indícios do enfraquecimento de uma ética da esfera pública no campo educacional.

Se tomarmos, por exemplo, o documento "Educação para todos: o compromisso de Dakar", do qual o Brasil foi um dos signatários em 2001, observa-se uma retórica de caráter salvacionista que coloca a educação, a equidade e a elevação da qualidade da aprendizagem, como a condição do desenvolvimento, da redução da pobreza, da empregabilidade, da in- 
serção na sociedade do conhecimento e na economia global, da paz e da estabilidade, de melhor qualidade de vida. O analfabetismo, os diferenciais na distribuição da riqueza, as desigualdades, especialmente de gênero, a marginalidade, a AIDS, os conflitos e as guerras, são as ansiedades, os perigos e as ameaças a serem confrontados e resgatados pela educação e pela inserção na economia global e na sociedade tecnológica (World..., 2001). Ainda no século XXI, permanece o ideal da educação moderna nas virtudes da ciência e do conhecimento humano.

As noções de cidadania presentes nesse documento, marcado pelo seu caráter global, pouco se referem a termos como coesão e solidariedade social construídas nas fronteiras do Estado-Nação, interdependência dos indivíduos, solidariedades assentadas em uma linguagem ou cultura comum. Tampouco a identidade é construída pela exaltação e o estímulo a uma memória histórica e a um conjunto de símbolos partilhados aos quais se deve lealdade, como já foi característico dos discursos educacionais oficiais de outros tempos. $\mathrm{O}$ bem comum, a construção da identidade nacional, o compromisso com projetos sociais coletivos como a Nação e a classe social, a preocupação com a ordem e a segurança territorial e ideológica são aspectos pouco enfatizados na ordem do discurso das políticas educacionais de nossos tempos.

As reformas educacionais ao redor do globo, sugere Popkewitz (2004), incorporam noções de cidadania baseada em subjetividades "cosmopolitas", sem pátria e sentimentos nacionalistas. As identidades são definidas preponderantemente em termos de traços e disposições de ordem cultural: tolerância, atenção e diálogo com os diferentes, aceitação das diversidades de gênero, étnicas, sexuais e dos grupos com necessidades especiais. A cidadania é definida em termos de habilidades necessárias a uma economia global e a uma sociedade do conhecimento, que se fundamenta na produção flexível, no uso da tecnologia, e sujeita a contratempos como o desemprego e a instabilidade do mercado de trabalho. São novas formas de comunitarismos e solidariedades que emergem em torno de e entre microcomunidades (a comunidade escolar, a comunidade de gênero, étnica, racial, o entorno da escola e da cidade etc.), acentuando responsabilidades locais e autogestão dos indivíduos. Cada um deve estar preparado para "melhorar suas vidas e transformar sua sociedade", e a educação deve oferecer a jovens e adultos "o acesso às técnicas e conhecimentos necessários para encontrar emprego remunerado e participar da sociedade" (World..., 2001, p. 8-9).

Em contrapartida, se tomarmos um documento curricular direcionado à educação brasileira, como são os Parâmetros Curriculares Nacionais (PCNs), vamos encontrar uma cidadania de matizes psicológicos e atenta a demandas mais locais, ainda que permaneçam alguns dos traços comentados anteriormente para o documento do Fórum de Dakar.

A cidadania, conforme é definida no primeiro volume que introduz os Parâmetros, alia a consciência crítica e a a ência ao desenvolvimento de habilidades que "possibilitem adaptações às complexas condições e alternativas de trabalho que temos hoje e a lidar com rapidez na produção e circulação de novos conhecimentos e informações [...]" (Brasil, MEC, 2001, p. 47).

Os padrões de uma identidade coletiva passam pela construção de uma identidade pessoal e cognitiva definida em termos preponderantemente psicológicos: "aprender a aprender", para desenvolver "competências" necessárias à provisoriedade de um mundo em constante transformação. Aprender a aprender, para desenvolver a autonomia. Atender e considerar as necessidades das comunidades próximas, "as expectativas e as necessidades dos alunos, dos pais, dos membros da comunidade, dos professores, enfim, dos envolvidos diretamente no processo educativo" (idem, p. 46-47), a fim de possibilitar a aprendizagem e o diálogo significativo da cultura local com a cultura escolar.

A autonomia é o princípio fundamental que os PCNs definem em termos de "iniciativa", "automotivação", "autoempreendimento", "autoenvolvimento e empenho pessoal". Inclui ainda "governar-se", "segurança" (qualidade psicológica), "autonomia intelectual" e moral (respeito mútuo e integração 
comunitária), discernimento, capacidade de "resolver problemas", "cuidado de si", "respeito a regras estabelecidas" e respeito à diversidade. As condutas abjetas são definidas em termos de: ansiedade diante dos desafios, medo do fracasso, sentimento de incapacidade, insegurança, isolamento e incapacidade de cooperar, bloqueio para aprender, autoconceito negativo que desencadeia indisciplina e comportamentos "problemáticos" (idem, p. 97-99). O pânico acerca da "baixa autoestima" e dos constantes fracassos dos aprendizes, que têm como consequência a ausência de autonomia dos indivíduos e de capacidade de iniciativa, merece um capítulo à parte no contexto dos Parâmetros.

Os discursos das reformas e das políticas educacionais no Brasil aliam enunciados relacionados com uma racionalidade eminentemente instrumental, que está no coração da tradição cultural e científica norte-americana, ou mesmo com os totalitarismos da performatividade denunciados por Ball (2001), a preocupações que produzem no imaginário a associação da educação e das reformas com a solução de questões relacionadas à conquista de igualdade e justiça social. É um tanto precipitado concluirmos que os discursos das reformas contemporâneas no Brasil estão postos estritamente em termos economicistas e isentos de preocupações de ordem social.

No Brasil, e mesmo nos documentos "exógenos" dirigidos aos países em desenvolvimento, o discurso educacional, por vezes, escapa a identidades definidas estritamente em termos "cosmopolitas" e econômicos. Nessas ocasiões, emergem formas de solidariedade que apostam em coletividades mais amplas, como a Nação, e no combate da exclusão de amplos setores marginalizados das virtudes da globalização.

Há um investimento em formas de subjetividade que privilegiam uma agência com consciência crítica e sensibilidade diante de questões nacionais como a "promoção do desenvolvimento sustentável" do país e a "superação das desigualdades sociais" (Brasil, Conselho Nacional de Educação, 2001). Falam sobre a vontade da política nacional de se "harmonizar com os objetivos fundamentais da própria república", como construir uma sociedade livre, justa e solidária; garan- tir o desenvolvimento nacional; erradicar a pobreza e a marginalização", "promover o bem de todos" etc. (Brasil, MEC, s.d., p. 5-6).

São assim discursos híbridos e contraditórios quando comparamos seus enunciados e as tecnologias políticas de governo que vêm sendo implementadas: híbridos nas proposições da organização curricular e didática (construtivismo, pedagogia das competências, disciplinas, temas transversais etc.), como muitos já apontaram (Lopes, 2005; Popkewitz, 2004; Ball, 2001); e híbridos também do ponto de vista dos imaginários nacionais e regimes éticos que propõem.

Isso se explica, em parte, pelo fato de que países como o Brasil apresentam grandes contrastes e desigualdades sociais e regionais, em que o tradicional e o moderno se superpõem e convivem lado a lado, não sem conflitos e negociações constantes. Muitas promessas da modernidade estão ainda longe de serem cumpridas amplamente, como, por exemplo, a universalização da escola elementar. Demandas locais e a pressão dos movimentos sociais - aqui ainda mais vivos que no norte do globo - disputam espaço e representação na arena econômica, política e cultural, com as demandas, nem sempre conciliáveis, relativas à inserção do Brasil em uma economia interdependente e altamente competitiva.

No Brasil, as racionalidades neoliberais na esfera educacional são objeto de intensas contestações, tendo os governos que recuar diante das dificuldades e dos embates que as medidas oficiais na maioria das vezes suscitam, seja pelo ativismo de esquerda da comunidade científica e dos sindicatos de professores, e/ou pelas dificuldades que essas políticas enfrentam no momento de serem recontextualizadas nas instituições educacionais. No entanto, os mecanismos de regulação e gestão e os regimes éticos aqui descritos têm avançado pelas reformas e governos das últimas décadas.

Como outros já disseram (Ball, 2001), governos de diferentes posições do espectro ideológico e político têm atualmente muito pouca diferença em suas políticas econômicas, sociais e culturais. A cultura da performatividade seduz uns e outros, homogeneizan- 
do, na maior parte das vezes, a linguagem da reforma ao redor do globo.

As políticas impulsionadas pela UNESCO e pelo Banco Mundial nos anos de 1980, em que pesem as diferenças de orientação entre esses organismos, tiveram por foco a expansão do número de matrículas na educação fundamental, em meio a uma crise mundial e desinvestimentos no campo social. Nos anos da década de 1990, o foco foi a reforma da escola e do sistema em bases gerenciais e o controle da qualidade da aprendizagem por meio da medição e elevação do desempenho escolar, controle instituído pelo monitoramento dos desempenhos das instituições escolares e dos alunos, tendo como base políticas de exames nacionais e índices como o IDEB. Atualmente essas políticas fazem já parte da rotina das escolas em todos os níveis de ensino.

A qualidade da educação resumiu-se ao rendimento escolar, ou à performatividade, estimulando ansiedades e a competição entre as escolas e os professores. Além disso, as políticas de avaliação nacional vêm intensificando o controle sobre o trabalho escolar e docente, desencadeando uma série de expedientes e casuísmos para atingir as médias de desempenho necessárias: o treinamento dos alunos para os exames, as classes de "aceleração", ou simplesmente a exclusão de alunos das classes populares, cujos desempenhos possam comprometer a imagem e os índices de desempenho da escola. Freitas (2007) caracteriza os efeitos de poder dessas políticas como "a ocultação da má qualidade de ensino" e a "exclusão adiada" das classes populares, pela assepsia dos números e a sedução das estatísticas. Ou seja, essas políticas, que pretensamente visam a elevar a qualidade da aprendizagem, estimulando a competição e uma lógica produtivista, contribuem para a instituição de novas formas de exclusão (a partir do interior das instituições) que naturalizam não só a lógica empresarial e economicista na escola, como atribuem aos próprios indivíduos e instituições escolares a responsabilidade pelos fracassos ou pelos sucessos, vistos como (falta de) empenhos e esforços individuais. Os exames nacionais colocam as instituições educacionais e seus agentes num campo de hierarquias e visibilidades, objetos de ações e programas gestados no MEC para a elevação dos índices de seu desempenho.

Os exames nacionais instituem uma política do conhecimento que tende a expulsar dos currículos escolares conteúdos e conhecimentos mais locais, cuja significação está diretamente relacionada às experiências culturais e modos de vida de comunidades locais e regionais. Ao mesmo tempo, legitimam a ideia de conhecimentos universalmente válidos e de uma cultura comum que privilegia o letramento, a matemática e "habilidades essenciais à vida" (World..., 2001, p. 9). Nessa fórmula estão conteúdos e habilidades relacionados a uma sociedade pós-industrial, baseada em uma razão tecnocrática, no individualismo, no consumismo e em uma ética hedonista.

As tecnologias políticas das atuais reformas na fabricação de regimes éticos baseados na autonomia, na automotivação e no autoempreendedorismo são a descentralização da gestão financeira e administrativa, a (auto)responsabilização e a corresponsabilização. Responsabilização que implica a desresponsabilização crescente do aparelho de Estado com o aporte dos recursos e condições para a melhoria da qualidade do trabalho educacional. Essas tecnologias parecem funcionar de modo pleno e eficiente no caso das políticas de avaliação nacional, porque elas unem as possibilidades dadas por uma visibilidade individualizadora e as "sanções" e ações necessárias à normalização dos seus desempenhos e à conduta de seus agentes. $\mathrm{O}$ próprio $\mathrm{PDE}$ reconhece que as políticas de avaliação nacional são a "base da regulação" (Brasil, MEC, s.d., p. 30-31).

Carnoy (2004), em artigo publicado pela revista Prelac, fórum de debate e divulgação das políticas de reforma educacional na América Latina e Caribe, publicada pela OREALC, avalia que os investimentos das políticas de reforma na descentralização do financiamento e da gestão escolar, na privatização e nas mudanças curriculares, adotadas pela região nos últimos vinte anos (décadas de 1980-1990), não apresentaram evidências de que tenham dado resultados em termos da melhoria do acesso e da aprendizagem 
para a grande maioria dos jovens da América Latina. As reformas na educação não só não melhoraram o desempenho do sistema, como aumentaram as desigualdades entre estudantes de extratos sociais com capital econômico e cultural diferentes.

Nesses termos, pode-se pensar que os discursos da reforma e da qualidade da educação tenham sido tomados de empréstimo para justificar o avanço das práticas de governo neoliberais e dos imaginários sociais e formas de subjetividade que as acompanham. Quero dizer, são vinte anos de investimentos em políticas, cujas "lições" mais significativas em nossos países parecem ter sido a reestruturação de nossas formas de pensamento sobre o social e das formas de governo e de gestão do Estado em bases gerencialistas.

\section{Referências bibliográficas}

ANADON, Simone B.; GARCIA, Maria Manuela. Trabalho escolar e docente nos discursos oficiais na revista "Nova Escola". Cadernos de Educação, Pelotas, n. 25, p. 133-145, jul./dez. 2005.

BALL, S. Diretrizes políticas globais e relações políticas locais em educação. Currículo sem Fronteiras, v. 1, n. 2, p.99-116, jul./dez. 2001. Disponível em: $<$ http://www.curriculosemfronteiras.org $>$. BAUMAN, Z. Globalização: as consequências humanas. Rio de Janeiro: Jorge Zahar, 1999.

BRASIL. Ministério da Educação. Plano de Desenvolvimento da Educação: razões, princípios e programas. Disponível em: $<\mathrm{http}: / /$ portal.mec.gov.br $>$.

BRASIL. Ministério da Educação. Parâmetros Curriculares Nacionais. Introdução. 3. ed. Brasília: Secretaria da Educação Fundamental, 2001.

BRASIL. Conselho Nacional de Educação. Parecer $C N E / C P$ 009/2001, de 8 de maio de 2001. Diretrizes Curriculares Nacionais para a Formação de Professores da Educação Básica, em nível superior, curso de licenciatura, de graduação plena. Publicado no Diário Oficial da União, Brasília, DF, seção 1., p. 31, 18 jan. 2002. Disponível em: <http://portal.mec.gov.br/cne/arquivos/pdf/009. pdf $>$. Acesso em: 3 mar. 2004.

CARNOY, Martin. Maior acesso, igualdade e qualidade na educação da América Latina: quais as lições para o Projeto Regional de Educação para a América Latina e o Caribe? Revista Prelac, ano 1, n. 0, p. 43-63, ago. 2004.
FOUCAULT, M. Agovernamentalidade. In: . Microfisica do poder. 9. ed. Rio de Janeiro: Graal, 1990. p.179-191.

. Arqueologia do saber. 4. ed. Rio de Janeiro: Forense Universitária, 1995.

FREITAS, L. C. de. Eliminação adiada: o ocaso das classes populares no interior da escola e a ocultação da (má) qualidade do ensino. Educação \& Sociedade, Campinas, vol. 28, n. 100 - Especial, p. 965-987, out. 2007.

GARCIA, Maria Manuela Alves. Texto e contexto: a reforma em cursos de Licenciatura na Universidade Federal de Pelotas (UFPel). In: REUNIÃO ANUAL DA ANPEd, 31., 2008, Caxambú-MG. Anais... Caxambú-MG: Rio de Janeiro: ANPEd, 2008. Constituição Brasileira, Direitos Humanos e Educação, v. 1. p. 1-16.

GARCIA, Maria Manuela Alves; ANADON, Simone Barreto. Reforma Educacional, intensificação e autointensificação do trabalho docente. Educação \& Sociedade, Campinas, v. 30, n. 106, p. 63-85, jan./abr. 2009.

LOPES, Alice Casimiro. Tensões entre recontextualização e hibridismo nas políticas de currículo. In: REUNIÃO ANUAL DA ANPEd, 28., 2005, Caxambú-MG. Anais... Caxambú-MG, 2005. McKEOWN, A. Periodizing globalization. History Workshop Journal. 63(1): 218-230, 2007.

PEREIRA, L. C. B. A reforma do aparelho do Estado e a constituição brasileira. Conferência nos seminários sobre a reforma constitucional realizados com os partidos políticos, sob o patrocínio da Presidência da República. Brasília, jan. 1995.

PETERS; MARSHALL; FITZSIMONS. Gerencialismo e política educacional em um contexto global: Foucault, neoliberalismo e a doutrina da autoadministração. In: BURBULES, N.; TORRES, C. A. e col. Globalização e educação: perspectivas críticas. Porto Alegre: ArtMed, 2004. p. 77-90.

POPKEWITZ, T. Inventing the modern self and John Dewey: modernities and the traveling of Pragmatism in Education - an introduction. In: Inventing the modern self and John Dewey: modernities and the traveling of Pragmatism in Education. New York: Palgrave Macmillan, 2005. p.3-36

Reforma educacional: uma política sociológica. Poder e conhecimento em educação. Porto Alegre: Artes Médicas, 1997. . A reforma como administração social da criança: a globalização do conhecimento e do poder. In: BURBULES, N.; TORRES, C. A. e col. Globalização e educação: perspectivas críticas. Porto Alegre: ArtMed, 2004. p. 107-125.

ROSE, N. Governing “advanced” liberal democracies. In: BARRY, 
A; OSBORNE, T.; ROSE, N. Foucault and political reason: liberalism, neo-liberalism and rationalities of government. Chicago: The University Chicago Press, 1996. p. 37-63.

WORLD EDUCATIONAL FÓRUM. Educação para todos: o compromisso de Dakar. 2. ed. Brasília: UNESCO;CONSED;Ação Educativa, 2001.

MARIA MANUELA ALVES GARCIA possui graduação em Licenciatura Plena em Pedagogia pela Universidade Federal de Pelotas (1986), Mestrado em Educação pela Universidade Federal de Minas Gerais (1994) e Doutorado em Educação pela Universidade Federal do Rio Grande do Sul (2000). Realizou estágio de pósdoutorado de outubro de 2006 a dezembro de 2007 na University of Wisconsin (UW), Madison (WI), E.U. A. , junto ao "Curriculum \& Instruction Department", no grupo de pesquisa do Prof. Thomas Popkewitz. É professora da Faculdade de Educação, Universidade Federal de Pelotas, atuando no Programa de Pós-Graduação em
Educação, curso de Mestrado e Doutorado, na Linha de Pesquisa “Currículo, Profissionalização e Trabalho Docente”. Desenvolve estudos e orienta investigações nas áreas de Currículo e Trabalho Docente, interessando-se sobretudo pelas problemáticas das Políticas Curriculares e das Reformas Educacionais em suas relações com os processos de trabalho docente e a formação de professores.

Nos últimos anos publicou, entre outros: Hypolito, A. M. ; Vieira, J. S.; Garcia, M.M.A. (Orgs.). Trabalho docente: formação e identidades (Pelotas, Seiva, 2002); Garcia, M.M.A.; Hypolito, A. M.; Vieira, J.S. As identidades docentes como fabricação da docência (Educação e Pesquisa, São Paulo, v. 31, n. 1, p. 45-56, jan./abr. 2005); Garcia, Maria Manuela Alves. Didática e trabalho ético na formação docente (Cadernos de Pesquisa, v. 39, n. 136, p. 225-242, jan./abr. 2009).E-mail: garciamariamanuela@gmail.com

Recebido em fevereiro de 2009 Aprovado em abril de 2010 
Maria Manuela Alves Garcia

\section{Políticas educacionais}

contemporâneas: tecnologias, imaginários e regimes éticos

Inspirado em um conjunto de estudos que problematizam o caráter global das reformas educacionais desde os anos de 1990 e nos estudos de Michel Foucault acerca do discurso e da governamentalidade, o artigo examina a racionalidade que tem pautado as atuais reformas educacionais, destacando suas principais tecnologias de governo e relações com a produção de imaginários sociais e regimes éticos dos indivíduos. A título de ilustração, apresenta enunciados dispersos em documentos oficiais produzidos no Brasil ou que apontam, de modo exógeno, para as formas de identidade e atuação desejadas para o sujeito econômico, político e educacional. Argumenta que os imaginários e os regimes do eu promovidos pelos discursos educacionais oficiais, no Brasil, têm um caráter híbrido, aliando preocupações economicistas e "cosmopolitas" a demandas locais, marcadas pela necessidade de justiça e igualdade social. Conclui que o discurso das reformas e de promoção da qualidade da educação vem sendo tomado de empréstimo 
para justificar o movimento de reorganização do Estado brasileiro em bases gerencialistas, não modificando substancialmente as condições de desigualdade educacional entre jovens oriundos de diferentes classes sociais.

Palavras-chave: reformas e educacionais; políticas educacionais; imaginários sociais; regimes éticos

Contemporary educational policies: technologies, imaginaries and ethical regimes

Based on a set of studies that question the global character of educational reforms since the 1990's, and on Michel Foucault's studies on discourse and on governmentality, the article examines the rationality that has ruled the present educational reforms, emphasising their main technologies of government and their relations with the production of social imaginaries and ethical regimes of individuals. It introduces, by way of illustration, enunciations scattered in official documents produced in Brazil or which, in an exogenous way, point to the desired forms of identity and performance for the economic, political and educational individual. It argues that the imaginaries and the regimes of self, promoted by the official educational discourse in Brazil, have a hybrid character, allying economicistic and "cosmopolitan" concerns with local demands characterized by the need for justice and social equality. It concludes that the discourse on the reforms and on the promotion of the quality of education has been borrowed to justify the movement to reorganize the Brazilian State on a managerialistic basis, and does not modify substantially the conditions of educational inequality among youths from different social classes.

Key words: educational reforms; educational policies; social imaginaries; ethical regimes

\section{Políticas de la educación} contemporáneas: tecnologías, imaginarios y regímenes éticos Inspirado en un conjunto de estudios que torna problemático el carácter global de las reformas de la educación desde los años de 1990 y los estudios de Michel Foucault a respecto del discurso y del carácter gubernamental, el artículo examina la racionalidad que ha relacionado las actuales reformas de la educación, destacando sus principales tecnologías de gobierno y relaciones con la producción de imaginarios sociales y regímenes éticos de los individuos Como título de ilustración, presenta enunciados dispersos en documentos oficiales producidos en Brasil o que apuntan, de modo exógeno, para las reformas de identidad y actuación deseadas para el sujeto económico, politico $y$ de la educación. Argumenta que los imaginarios y los regímenes del yo promovidos por los discursos oficiales de la educación, en Brasil, tienen un carácter híbrido, aliando preocupaciones economicistas y "cosmopolitas" a demandas locales, marcadas por la necesidad de justicia e igualdad social. Concluye que el discurso de las reformas y de promoción de la calidad de la educación, viene siendo tomado como préstamo para justificar el movimiento de reorganización del Estado brasileño en bases gerenciales, no modificando sustancialmente las condiciones de desigualdad de educación entre los jóvenes oriundos de diferentes clases sociales.

Palabras clave: reformas y educación; políticas de la educación; imaginarios sociales; regímenes éticos 